Jurnal Pengetahuan, Pemikiran dan Kajian Tentang Bunyi

Vol. X., No. X, Mei 2021, hal. 111-131

ISSN 1412-2065, eISSN 2714-6367

https://jurnal.isi-ska.ac.id/index.php/keteg

\title{
CENGKOK GENDERAN DUALOLO SEBAGAI SUMBER IDE PENCIPTAAN KOMPOSISI MUSIK “FANTASIA FROM DUALOLO”
}

\author{
F. Purwa Askanta \\ Jurusan Karawitan, \\ Institut Seni Indonesia Surakarta, \\ Jl. Ki Hadjar Dewantara No 19 Kentingan, \\ Jebres, Surakarta (57126), Jawa Tengah, \\ Indonesia \\ askanta@isi-ska.ac.id \\ *Penulis Korespondensi
}

\author{
Danis Sugiyanto \\ Jurusan Karawitan, \\ Institut Seni Indonesia Surakarta, \\ Jl. Ki Hadjar Dewantara No 19 Kentingan, \\ Jebres, Surakarta (57126), Jawa Tengah, \\ Indonesia \\ danis@isi-ska.ac.id
}

dikirim 03-08-2021; diterima 03-08-2021; diterbitkan 21-09-2021

\begin{abstract}
Abstrak
Artikel ini berjudul Cengkok Genderan Dualolo Sebagai Sumber Ide Penciptaan Komposisi Musik "Fantasia From Dualolo". Fokus permasalahan yang dikaji dalam tulisan ini meliputi analisa karya komposisi musik yang menggunakan sumber ide kekaryaan dari sebuah cengkok genderan dualolo dalam Karawitan Jawa. Bagaimana ide tersebut digunakan sebagai tema serta dikembangkan hingga tersusun menjadi sebuah bangunan bunyi yang berbentuk Fantasia dalam tiga bagian. Dalam komposisi ini terdapat beberapa sistem penciptaan yang perlu diungkapkan guna pemahaman terhadap pembaca agar mengerti tentang konsep penciptaan karya musik ini. Metode yang digunakan dalam artikel ini adalah deskriptif analisis dengan pendekatan ilmu bentuk analisis musik. Temuan hasil penelitian ini akan menunjukkan kreativitas dalam penyusunan sebuah komposisi musik baru yang dilakukan oleh komponis. Sedangkan tujuan penelitian ini memberi kontribusi berupa teknik dan metode penciptaan karya musik yang mengangkat sebuah ide sederhana dari unsur tradisi karawitan Jawa yang berupa cengkok genderan dualolo. Diharapkan tulisan dalam artikel ini dapat menambah wawasan pembaca dan menjadi referensi bagi yang mendalami penciptaan musik.
\end{abstract}

Kata Kunci: Komposisi Musik, Konsep, Analisis, Cengkok, Dualolo

This work is licensed under a Creative Commons Attribution-ShareAlike 4.0

\begin{abstract}
This article is entitled Cengkok Genderan Dualolo as a Ideas for the Creation of Fantasia From Dualolo Music Composition. The focus of the problems studied in this paper includes the analysis of musical composition works that use the source of artistic ideas from a dualolo genderan twist in Javanese Karawitan. How the idea is used as a theme and developed to form a sound building in the form of Fantasia in three parts. In this composition, there are several creation systems that need to be expressed in order to understand the reader in order to understand the concept of creating this musical work. The method used in this articlel is descriptive analysis with a form of music analysis approach. The findings of this research will show creativity in composing a new musical composition by composer. Meanwhile, the purpose of this research is to contribute in the form of techniques and methods of creating musical works that raise a simple idea from elements of the Javanese musical tradition in the form of the dualolo gendered twisted. It is hoped that the writings in this journal can broaden the readers' insight and become a reference for those who explore the creation of musical works.
\end{abstract}


Keywords: Music compositionc, Concept, Analysis, Cengkok, Dualolo

\section{Pendahuluan}

Proses penciptaan komposisi musik membutuhkan kreativitas agar bangunan bunyi yang disusun dapat menjadi kesatuan bentuk, dimana bentuk tersebut sesuai dengan konsep yang dikehendaki oleh komponis. Faktor kreativitas penciptaan tersebut bersifat mandiri disesuaikan dengan konsep yang sudah dipikirkan dan dipertimbangkan. Untuk menyusun bunyi menjadi sebuah bangunan kesatuan bentuk dibutuhkan kreativitas individu, seperti apa yang diungkapkan oleh Primadi (1978) bahwa salah satu ciri kreasi adalah kelayakan-estetis-etis, yang merupakan sebuah perwujudan ciri pribadi kritis, yang dapat dipahami sebagai kreativitas yang dibatasi oleh norma estetis-etik yang berlaku. Kreativitas juga bisa mengutamakan pembaruan dalam menyusun sebuah musik. Hal tersebut ditandaskan oleh Oriana Tio Parahita Nainggolan (2019), bahwa kebaruan yang dimaksud adalah sesuatu yang belum pernah diciptakan sebelumnya dan lahir dari elaborasi ide-ide musikal. Sedangkan menurut Bambang Sunarto, metode penciptaan seni membutuhkan beberapa aspek yaitu, (1) keyakinan dasar, (2) nilai-nilai, (3) kehendak berkarya, (4) model, (5) konsep, (6) metode pengembangan konsep, (7) metode penerapan konsep, (8) karya seni (Sunarto 2013).

Bentuk musik dapat dimaknai sebagai perwujudan ide-ide atau emosi yang terbangun dalam susunan karya musik yang bermakna, seperti pendapat Budi Linggiono, bahwa untuk dapat menemukan makna dalam musik dapat diawali dengan memahami bagaimana proses penciptaannya. Dalam hal ini bagaimana mengerti sebuah ide muncul kemudian diformulasikan menjadi musik melalui gambaran bentuk (Linggono 1993).

Dalam memahami bentuk sebuah musik, dibutuhkan pendekatan ilmu yang membahas mengenai skema dan struktur musik. Ilmu bentuk dan analisis musik digunakan sebagai dasar untuk melihat keseluruhan komposisi yang akan dianalisis. Bentuk lagu adalah suatu kesatuan utuh dari satu atau beberapa kalimat dengan penutup yang meyakinkan. Kalimat- kalimat musik dapat disusun dengan memakai bermacam-macam bentuk (Prier dalam Rachman 2013).

Komposisi musik yang dianalisis dalam artikel ini menggunakan bentuk fantasia. Dalam sejarah musik barat fantasia merupakan salah satu bentuk musik yang banyak digunakan pada periode Renesance, suatu fase dimana musik keduniawian tumbuh dan berkembang (Pasaribu 1953). Hal serupa juga ditegaskan oleh Hugh M. Miller dalam bukunya yang berjudul Pengantar Apresiasi Musik, yang menjelaskan bahwa "Fantasia dan Capriccio keduanya menunjukan sebuah komposisi yang riang dan bebas..." (Miller 2017) hal itu juga ditegaskan dalam kamus musik yang ditulis oleh Pono Banue, menjelaskan bahwa Fantasia merupakan musik pholyphonik yang mempunyai gaya bebas dan berkembang pada abad 16-17 (Banoe 2003). Gaya bebas yang dimaksud disebabkan karena dalam fantasia mempunyai karakter kebebasan tafsir terhadap sesuatu yang digunakan sebagai sumber fantasinya, oleh sebab itu bentuk komposisi Fantasia berdasar pada kekuatan imajinasi dan keamampuan hayalan yang dimiliki oleh komposernya. Perlu kami jelaskan yang dimaksud musik poliponi merupakan musik yang berkembang pada periode Barok dan Rococo yang menggunakan dua atau lebih melodi yang terjalin dalam satu kesatuan, hal itu ditegaskan oleh Victor Ganap yang mengatakan bahwa polifoni merupakan penampilan dua melodi atau lebih secara bersamaan dalam bobot yang sama (Ganap 1986). 
Komposisi ini merupakan karya musik absolut dalam pengertian musik yang tidak mempunyai kandungan atau latar belakang cerita didalamnya. Karya komposisi ini hanya mempertimbangan keindahan musik itu sendiri. Musik absolut diartikan sebagai musik yang berisi aspek-aspek musikal tanpa ada penambahan atau pengaruh lain diluar unsur music (Dasanta 2017).

Sementara itu lawan dari musik absolut adalah music program. Musik program yang merupakan bentuk musik yang mempunyai latar belakang cerita. Motif-motif melodi dalam komposisi musik programa diciptakan berdasarkan imajinasi komponis untuk mewakili atau menggambarkan suatu tokoh, suasana, atau karakter Musik programa berbeda dengan musik absolute, hal itu dapat dilihat dari cara atau usaha dalam mengilustrasikan suatu objek (Hadaci 2018).

Tradisi adalah sumber ide penciptaan yang tiada habisnya (Sadra dalam Sugiyanto 2020). Oleh karena itu, komposisi ini menggunakan tradisi sebagai sumbernya. Sumber ide penciptaan komposisi berasal dari cengkok genderan dualolo. Pemahaman kata cengkok menurut Martopangrawit (1975) dalam tulisanya yang berjudul "Pengetahuan Karawitan II" terbagi menjadi dua,

1. Cengkok yang berarti garap adalah satu lagu yang permanen (tidak berubah) baik suara manusia maupun suara gamelan.

2. Cengkok yang berarti jumlah gong pada suatu gending yang biasa digunakan pada gendinggending tertentu.

Sedangkan istilah cengkok menurut Supanggah merupakan konfigurasi nada dan/atau ritme yang telah ditentukan ukuran panjangnya dan konfigurasi itu bisa abstrak atau imajiner (Supanggah 2009). Kemudian genderan berarti tafsir, imajinasi dan kreatifitas seorang penggender untuk menentukan pola, teknik dan gaya dalam memainkan ricikan gender (Pambayun 2020).

Dari uraian diatas dapat dipahami bahwa cengkok adalah sebuah bentuk atau wujud yang dapat digunakan sebagai penanda proses kreatif pengrawit dalam menafsir motif dan/atau melodi menjadi melodi baru yang tidak terlepas dari melodi yang ditafsir sesuai dengan karakter instrumennya. Selain hal tersebut cengkok juga bisa dipahami sebagai kesepakatan dalam menyajikan gending-gending tertentu yang berkaitan dengan bentuk sajian.

Gender salah satu intrumen dalam perangkat gamelan Jawa, yang dalam keberadaanya terdapat dua jenis gender yaitu gender barung dan gender penerus. Gender barung adalah gender yang ukurannya besar baik kerangka maupun bentuk bilahnya, sedangkan jangkauan nadanya adalah dari nada 6 sampai nada 3. Menurut Soeroso, menyebutkan jangkauan nada tersebut termasuk deretan gembyang yang ke IV, V dan setengah gembyang ke VI dari seluruh jangkauan nada pada gamelan jawa (Soeroso 1983).

Terkait pengetrapan cengkok dalam instrumen gender yang biasa disebut cengkok genderan dapat dipahami seperti pada uraian diatas namun disesuaiakan dengan karakter dan teknik yang ada pada instrumen gender. Hasil yang didapat dari tafsir tersebut bisa berupa motif, frase atau kalimat lagu.

\section{Metode}

Karya komposisi "Fantasia From Dualolo" merupakan susunan komposisi dengan penggarapan menggunakan disiplin musik barat yang mana penyusun menuliskan seluruh ide karya kedalam tulisan atau notasi musik. Pengembangan ide dasar yang digunakan sebagai tema dalam komposisi ini merupakan hal terpenting, karena tema tersebut diolah berdasar pada teknik- 
teknik komposisitoris musik barat seperti augmentasi, diminusi, pengembangan ritmikal maupun pengembangan secara melodis. Dalam analisis ini penulis menggunakan metode observasi sebagai pijakan dalam mencari bahan dasar untuk pengembangan lebih lanjut. Adapun tahapan observasi ini diperlukan langkah-langkah guna memahami dan menguak bagaimana pengembangan tema dalam karya komposisi. Adapun metode yang digunakan adalah :

Studi Pustaka

1. Mencari materi yang berkaitan dengan ide penyusunan karya komposisi.

2. Membandingkan materi yg sesuai dengan ide penyusunan karya komposisi.

3. Menentukan materi sebagai ide dasar penyusunan komposisi.

Studi Audiotif

1. Mendalami ide dasar yang dipilih secara audiotif

2. Mencari karakter ide dasar yang dipilih secara audiotif

3. Membandingkan penggunaan ide dasar berdasar permainan dan pengembangannya.

Pengamatan notasi musik per bagian komposisi.

1. Dalam penyesuaian karakter ide dasar komposisi.

2. Kesesuaian ambitus sesuai dengan karakter ide dasar dan ide komposisi.

3. Mencari kemungkinan-kemungkinan untuk mewadai pengembangan ide dasar kompositoris.

4. Kesesuaian dengan instrumen yang digunakan.

Menentukan variasi pengembangan tema

1. Menentukan pengembangan tema pada komposisi Bagian satu.

2. Menentukan pengembangan tema pada komposisi Bagian dua.

3. Menentukan pengembangan tema pada komposisi Bagian tiga.

\section{Pembahasan}

Komposisi musik “Fantasi From Dualolo" adalah sebuah komposisi yang terdiri tiga bagian, pada bagian pertama menggunakan tempo sedang, bagian kedua tempo lambat dan bagian ketiga temponya cepat. Instrumen yang digunakan dalam komposisi ini merupakan gabungan dari instrumen musik rakyat Banyumas yaitu instrument calung, digabungkan dengan instrumen musik Barat berupa Flute dan biola. Calung Banyumas merupakan sebuah ensambel yang tumbuh dan perkembang di Banyumas yang biasa untuk mengiringi Lengger, seperti yang dikatakan Dyah Tjaturrini, bahwa tari lengger ini tidak pernah terpisah dengan calung sebagai musik pengiringnya (Tjaturrini 2018). Kesenian Calung Banyumas ini menjadi kebanggan daerahnya maka keberadaannya sangat diperhatikan dilestarikan, dan dijaga, ditegaskan juga oleh Suharto, bahwa Pemerintah Daerah juga memfasilitasi dalam pengembangan pendidikan seni tradisi khususnya seni Calung Banyumasan seperti dukungan penyelenggaraan Pendidikan SMK Negeri 3 Banyumas (Suharto 2018).

Format instrumen yang digunakan dalam komposisi ini terdiri dari dua gambang, satu dhem-dhem, dua flute dan dua biola. Dalam penamaan instrumen ini gambang disebut sebagai calung satu sedangkan gambang penerus disebut sebagai calung dua, hal itu dikarenakan untuk memudahkan penyususnan komposisi, mengingat istilah gambang sudah melekat dengan fungsinya dalam ansmbel tersebut. 
Konsep karya fantasi from dualolo ini mengangkat kesejajaran sistem laras slendro dan tonal minor pentatonik. Dalam laras slendro terdapat susunan nada,

\section{$\begin{array}{llllll}6 & 1 & 2 & 3 & 5 & 6\end{array}$}

atau dalam sebutan, Nem - Ji - Ro - Lu - Mo - Nem . Laras slendro tersebut memiliki rasa interval yang disejajarkan dengan system tangga nada minor pentatonik yang mempunyai urutan nada

\section{$\begin{array}{llllll}6 & 1 & 2 & 3 & 5 & 6\end{array}$}

yang dalam sebutan La - Do - Re - Mi - Sol - La. Dari konsep kesetaraan antara sistem laras slendro dan tonal minor diatonis tersebut penyusun mempunyai keyakinan munculnya sebuah karakter tonalitas baru yang tidak sama dengan karakter tonalitas yang sudah ada. Hal itu disebabkan karena kedua sistem tersebut masing-masing memiliki rasa interval yang berbeda tetapi ada kemiripan .

Dalam pengolahan instrumentasi komposisi Fantasi From Dualolo ini sistem laras slendro dimainkan oleh instrumen ansambel calung Banyumas dengan laras slendro asli atau tidak ada penyesuaian terhadap sistem pelarasan tonalitas diatonis Barat. Pada sestem tangga nada minor diatonis instrumen yang digunakan adalah isnstrumen tiup kayu yaitu dua flute dan dua instrumen gesek dua biola. Alasan pemilihan instrumen dalam karya tersebut berdasarkan pertimbangan karakter bunyi yang dimiliki oleh masing-masing instrumen, ansambel calung memiliki karakter nada-nada pendek apabila dipukul. Sedang instrumen flut dan biola mempunya karakter suara cenderung panjang. Dari dua karakter tersebut akan saling melengkapi dan menjadi perpaduan yang menarik. Selain pertimbangan karakter tersebut penyusun juga memiliki pertimbangan yang terkait dengan keterpengaruan rasa pada instrumen yang produksi nada-nadanya sudah baku tau tidak dapat berubah. Dalam hal ini ansambel calung Banyumas merupakan instrumen yang memproduksi nada-nada yang sudah baku, sedangkan flute dan biola dapat memproduksi nadanada yang fleksibel atau bisa berubah sesuai kebutuhan yang diharapkan. Dengan pertimbangan perpaduan instrumentasi tersebut diharapkan akan ada keterpengaruhan rasa pada instrumen flute dan biola dalam memproduksi nada atau dapat menyesuaikan dengan laras slendro pada instrumen calung Banyumas.

Terlepas dari cengkok yang mempunyai sifat abstrak ataupun imajiner, cengkok yang dapat ditemui pada notasi-notasi cengkok genderan dualolo adalah seperti notasi yang ditulis Martopangrawit (Martopangrawit 1972) dibawah ini, yang digunakan sebagai sumber atau ide dasar dalam penyusunan komposisi ini.

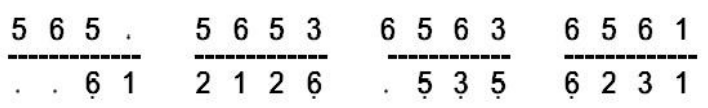

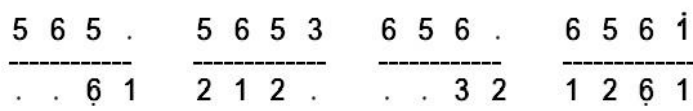


Cengkok genderan dualolo tersebut ditafsir penyuun menjadi satu garis melodi menjadi, seperti pada contoh dibawah ini.

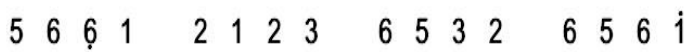

Setelah diterjemahkan dalam hayalan penyusun melodi tersebut diatas menjadi seperti notasi balok dibawah ini.

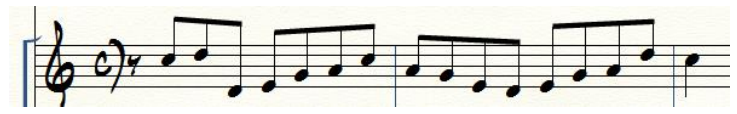

Tema melodi tersebut diatas digunakan sebagai ide dasar dalam penyusunan komposisi ini dengan berbagai pengembangannya sesuai dengan imajinasi penyusun.

1. Bagian Pertama

Pada bagian awal koposisi, tema muncul secara utuh tanpa untuk ditunjukan sebagaimana melodi yang digunakan sebagai ide dasar dalam penciptaan karya komposisi musik ini,. Pemahaman tentang tema dijelaskan oleh Adam Sila Sektian (Sektian 2016) yang mengutip pendapat Banoe (Banoe 2003), tema adalah lagu pokok yang menjadi landasan pengembangan lagu, serangkaian melodi atau kalimat lagu yang merupakan elemen utama dalam konstruksi sebuah komposisi; melodi pokok yang polanya selalu diulang-ulang dan dapat diuraikan dalam berbagai variasi.

Pada bagian pertama tempo yang digunakan adalah lambat dengan maksud agar tema dan pengembangannya dapat terlihat dengan jelas. Tema pokok tersebut tampil dalam permaianan instrumen calung satu dan didukung oleh melodi sub tema yang mengalami pelebaran (augmentasi) secara nilai nada dalam jangkauan suara rendah yang dimainkan oleh dhem-dhem. Seperti pada contoh notasi dibawah ini.

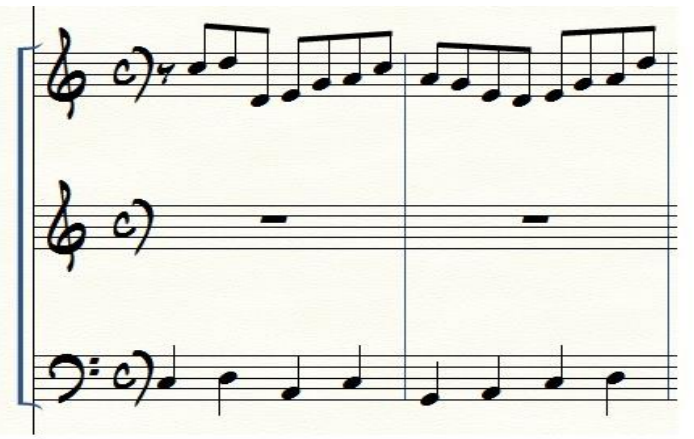

Kemudian tema tersebut dipersempit (diminusi) menjadi beberapa bagian yang berkembang menjadi motif kecil yang saling terkait hingga membentuk figurasi irama yang berfungsi sebagai iringan tema pokok yang akan muncul kemudian. Adapun motif-motif tersebut, seperti notasi dibawah ini.

Motif 1 


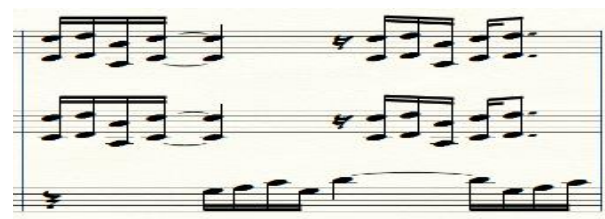

Motif 2

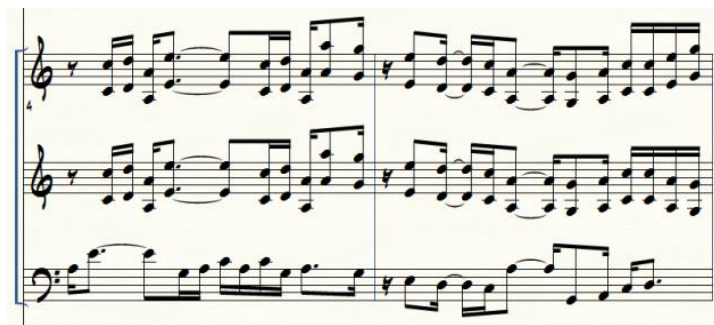

\section{Motif 3}

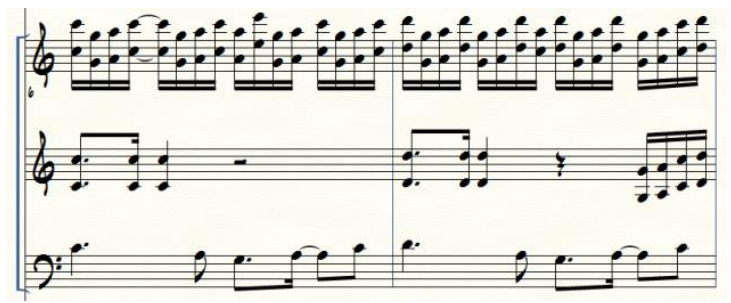

Motif 4

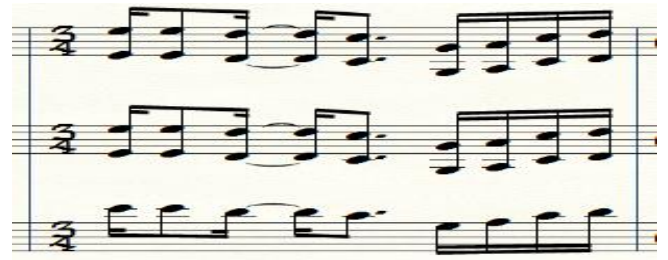

Dari motif-motif baru tersebut menjadi kesatuan yang membentuk kalimat lagu dan berfungsi sebagai intro atau pembuka lagu bagian pertama ini.

Seterusnya tema pokok mengalami perubahan secara ritme atau dipotong setengah menjadi motif baru dengan nilai ketukan seperenambelas, seperti contoh dibawah ini.

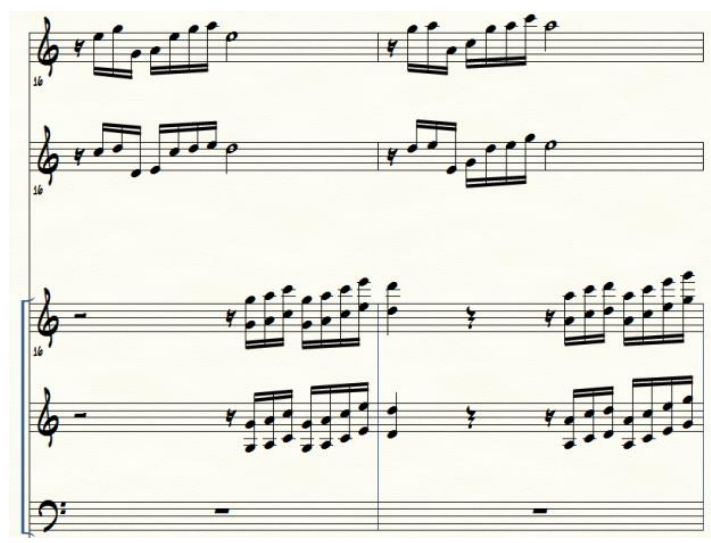

Motif baru tersebut dimainkan secara bergantian antara instrumen biola, flut dan calung, sekaligus masuk pada lagu utama. Selanjutnya tema dikembangkan secara ritmikal pada nilai 
ketukan seperenambelasan dan dimainkan dalam variasi tingkatan tonal yang berbeda, sedang instrumen calung berfungsi sebagai pemberi tekanan ditempat tempat tertentu untuk membangun kesan musikal yang baru. Seperti pada contoh notasi dibawah ini.

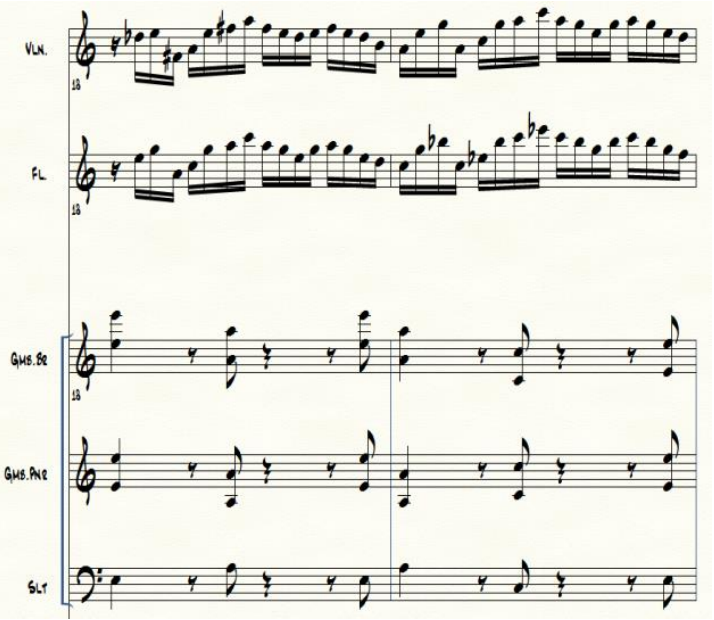

Untuk mengakhiri pengembangan tema-tema diatas, tema pokok dimunculkan kembali secara utuh dimainkan oleh instrumen biola dan dijadikan satu dengan tema yang sudah dipersmpit menjadi melodi dalam ritme seperenambelas yang dimainkan oleh instrumen calung, seperti pada notasi ini.



Sebagai menutup bagian pertama dimunculkan beberapa motif-motif baru, yang tersusun saling berkaitan membentuk melodi dalam kalimat lagu dan dalam satu kesan penyelesaian seluru rangkain bagian pertama dalam komposisi ini, seperti pada contoh notasi dibawah ini. 




\section{Bagian Kedua}

Bagian kedua komposisi musik "Fantasi From Dualolo" menggunakan tempo lambat, diharapkan tempo ini akan mampu menjadi wadah untuk mengembangkan tema pokok secara lebih luas.

Material tema yang dikembangkan masih sama dengan bagian pertama tetapi secara pengembangannya dapat melahirkan motif dan ana (sub) tema baru secara lebih variatif. Hal tersebut bisa dilihat dalam uraian berikut ini.

Awal bagian kedua komposisi ini Instrumen Dhem-dhem memaintan sebuah motif yang diulang-ulang membentuk ostinato, yang ditegaskan oleh Rina Wulandari (2016:5) yang mengutip Safriena (1999:177) menyatakan bahwa pola irama mempunyai padanan kata yaitu ostinato irama yang artinya pola irama yang dibunyikan atau didengar berulang-ulang. Dalam komposisi ini ostinato berfungsi sebagai dasar yang diperkuat oleh motif-motif lain menjadi kesatuan, membentuk kalimat lagu yang digunakan untuk mengiringi melodi yang terbangun pada tema pokok. Adapun motif dan melodi tersebut seperti contoh notasi dibawah ini.

Ostinato dimainkan imstrumen Dhem-dhem.

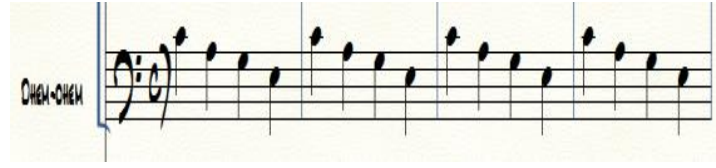

Perpaduan dengan motif-motif lain menjadi seperti contoh notasi dibawah ini. 


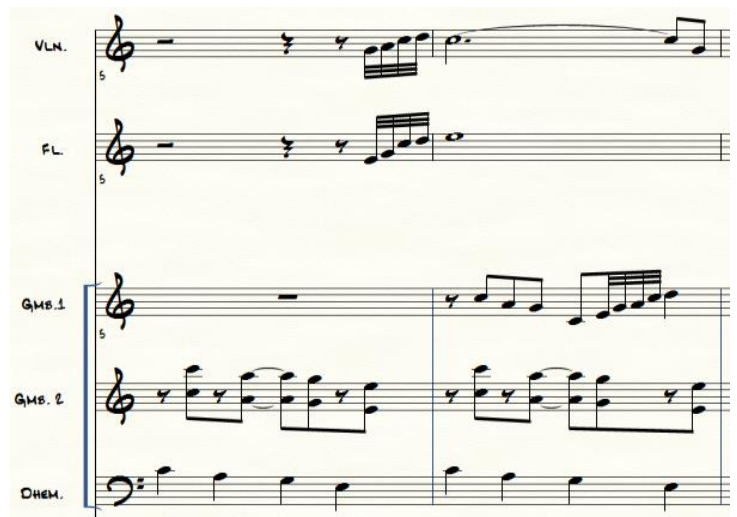

Setelah dibuka dengan motif-motif baru tersebut kemudian tema pokok muncul di berberapa tempat yang membentuk melodi pendek dan saling terkait, seperti pada contoh notasi dibawah ini.

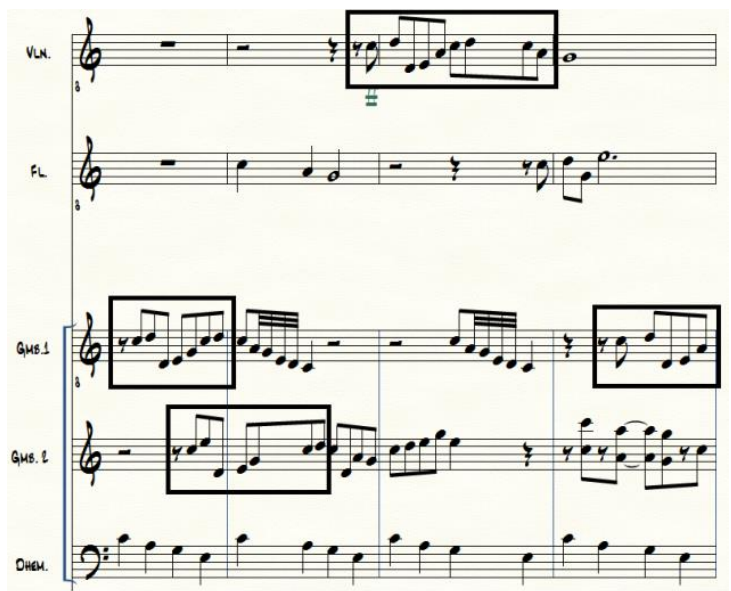

Kemudian tampil motif-motif baru membentuk pola iringan yang saling terkaiti antara motif 1, motif 2 dan motif 3 dalam tempo lebih cepat yang dimainkan ansambel calung dan berfungsi sebagai iringan tema pokok sekaligus membentuk kesan musikal baru dalam bagian kedua ini.

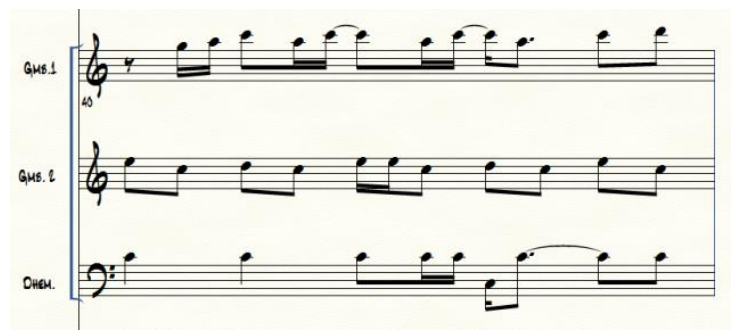

Tema pokok kembali muncul dalam satu frase melodi pendek yang mengalami perubahan secara ritmikal, seperti pada contoh notasi ini. 


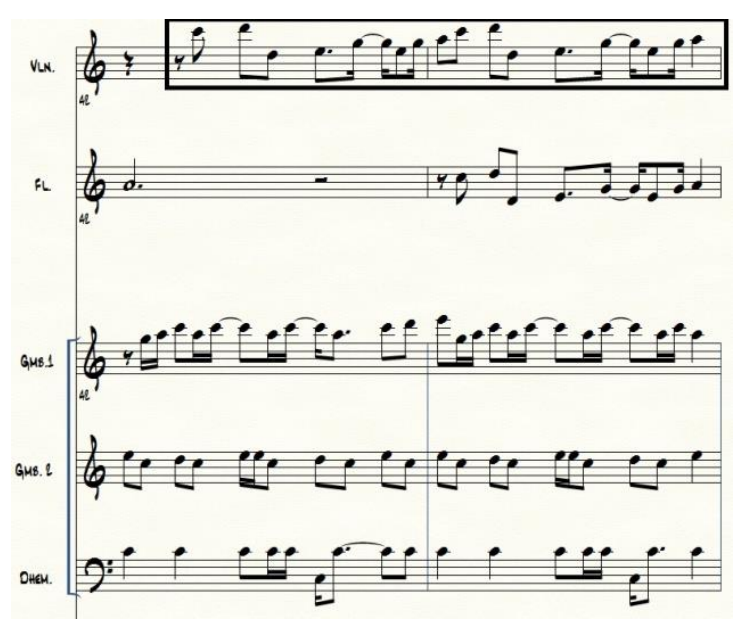

Seterusnya tema berubah menjadi frase-fraser pendek diulang-ulang dan membentuk kesan irama yang dimainkan oleh insrtumen biola dan flute secara unison dan kesan irama tersebut diperkuat oleh instrumen calung yang memainkan motif baru berupa akasen-aksen guna menegaskan motif-motif pada instrumen flute dan biola. Adapaun contohnya seperti notasi berikut ini.

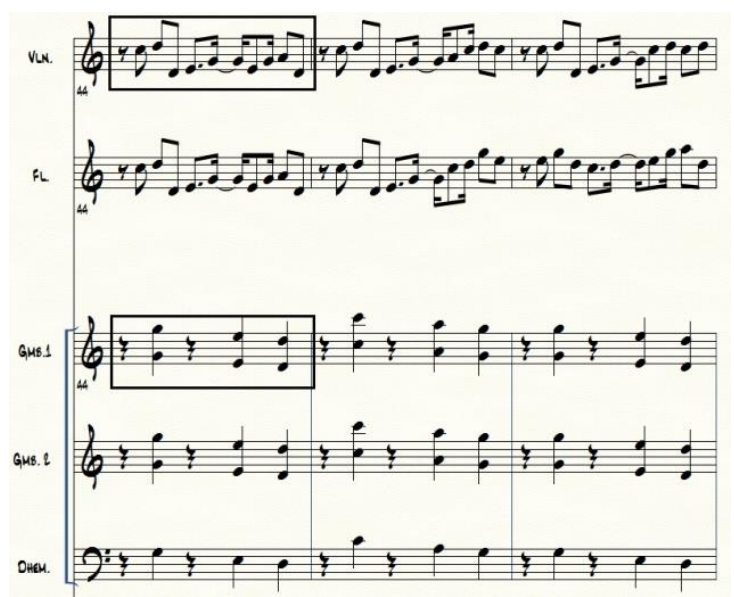

Selanjutnya motif baru kembali muncul pada instrumen flut yang berupa nada-nada kromatis dalam nilai ketukan seperenambelas. Motif tersebut digunakan sebagai penegas menuju kesan klimak sebelum bangunan kesan lagu diakhiri, seperti contoh notasi ini.

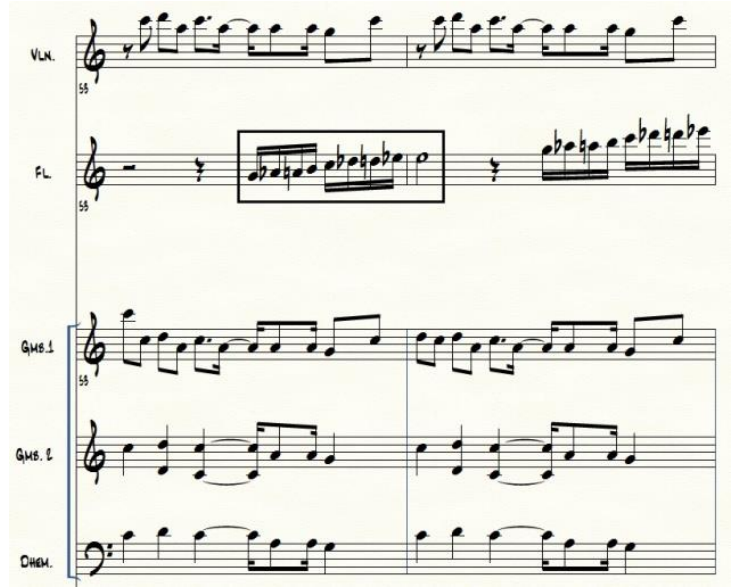




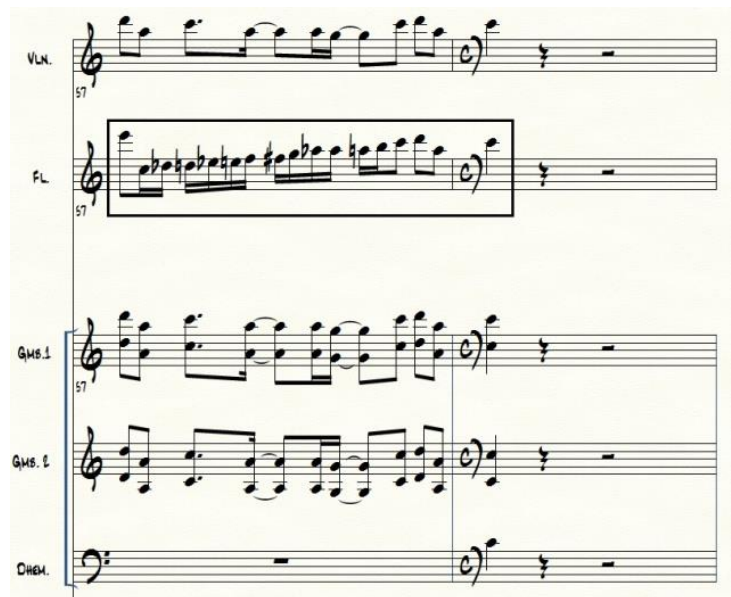

Kemudian dilanjutkan dengan bangunan kesan baru yang dimulai denga perkusi atau instrumen jimbe memainkan motif, seperti contoh notasi dibawah ini.

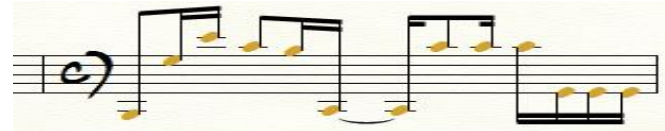

Setelah beberapa saat, motif ritmik baru muncul pada instrumen calung 1 dan dhem-dhem yang mengisi pola irama perkusi dan membentuk iringan.



Tema pokok divariasi menjadi bentuk bangunan lagu baru yang dimainkan secara bergantian antara flut dan biola. Seperti contoh dibawah ini.



Seterusnya muncul motif baru yang berfungsi sebagai penutup bangunan kesan lagu bentuk pertama pada bagian kedua ini. Pada bagian terakir berupa motif yang dimainkan semua instrumen secara unisono, seperti contoh notasi ini. 


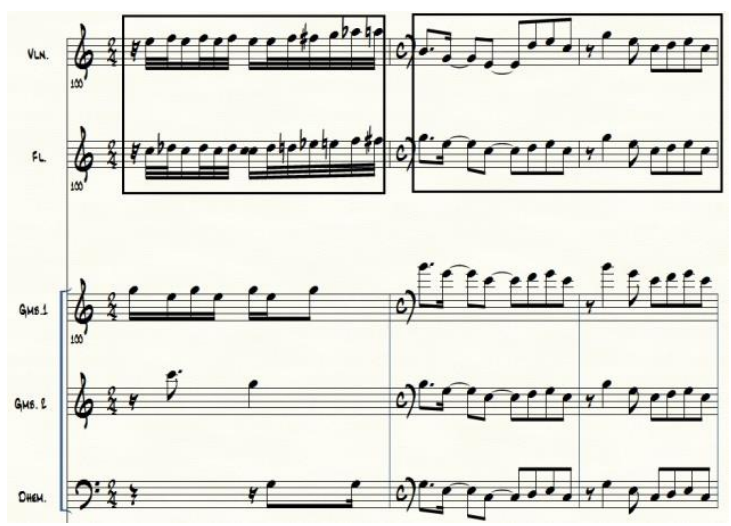

Bentuk bangunan kesan baru tersusun lagi sebagai penutup pada keseluruhan bagian kedua ini. Bentuk tersebut berupa gabungan dari beberapa motif yang menjadi kesatuan kalimat lagu dan mempunyai kesan klimak dengan variasi sukat 5/4, 3/4, dan 4/4, yang berakhir dengan munculnya tema pokok yang sudah mengalami modifikasi nada-nadanya, seperti contoh notasi dibawah ini.



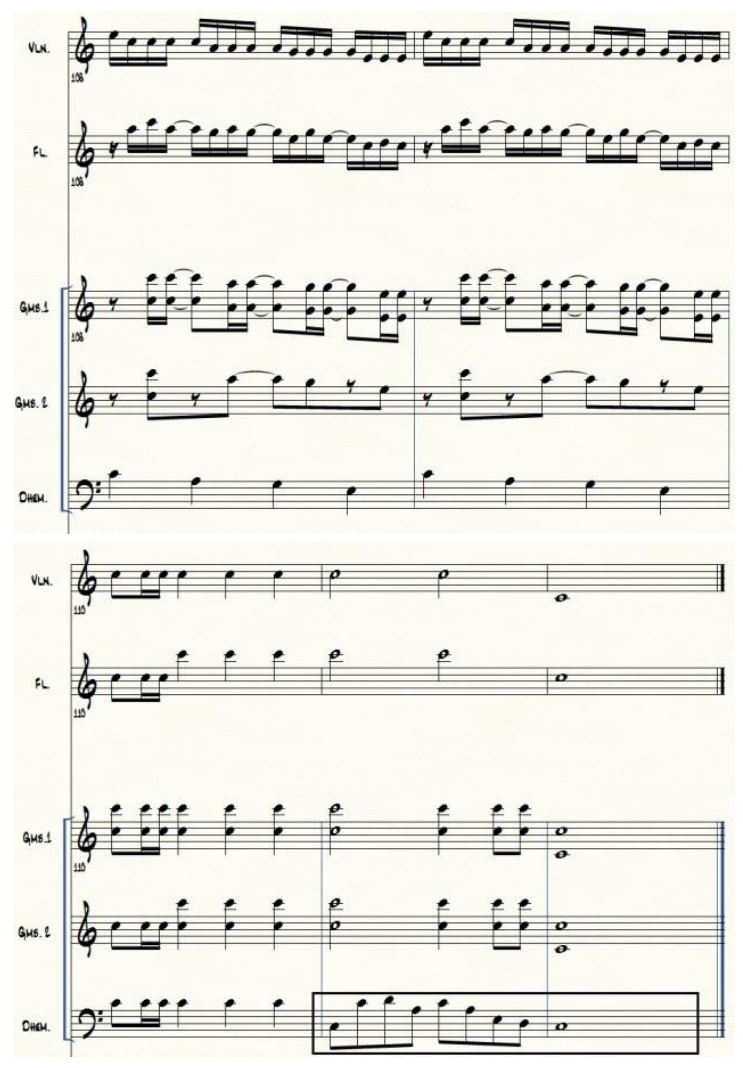

\section{Bagian Ketiga}

Bagian ketiga ini merupakan bagian terakhir dari keseluruhan karya komposisi musik "Fantasia From Dualolo. Pada bagian ini tema pokok banyak mengalami pengembangan bahkan muncul tema-tema baru yang tidak meninggalkan kesan tema pokok. Pada bagian ketiga ini menggunakan tempo cepat dengan harapan kesan sebagai penutup keseluruhan bagian tersampaikan.

Motif baru yang dimunculkan sebagai pembuka bagian ini, seperti contoh dibawah ini.



Motif-motif yang saling berkaitan antara ketiga instrumen calung ini membangun kesan jalinan melodi yang bersemangat dalam membuka bagian terahir komposisi ini.

Kemudian disusul oleh motif melodis yang dimainkan instrumen flute yang berialog dengan instrumen dhem-dhem diiringi gambang satu dan gambang dua dalam motif yang berbeda. 


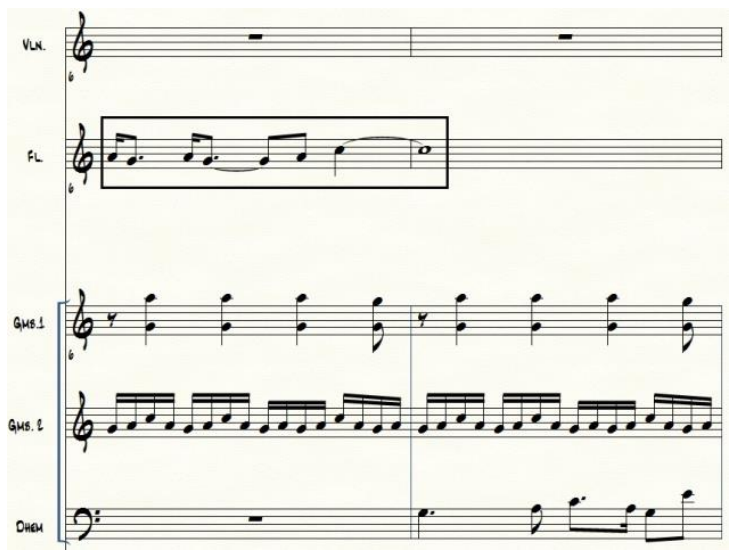

Motif baru muncul sebagai penutup dari intro pada bagian ini. Selanjutnya instrumen flute memainkan melodi baru sebagai sub tema pokok dalam sukat $5 / 4$, sedangkan calung memainkan motif-motif baru sebagi pengiring.

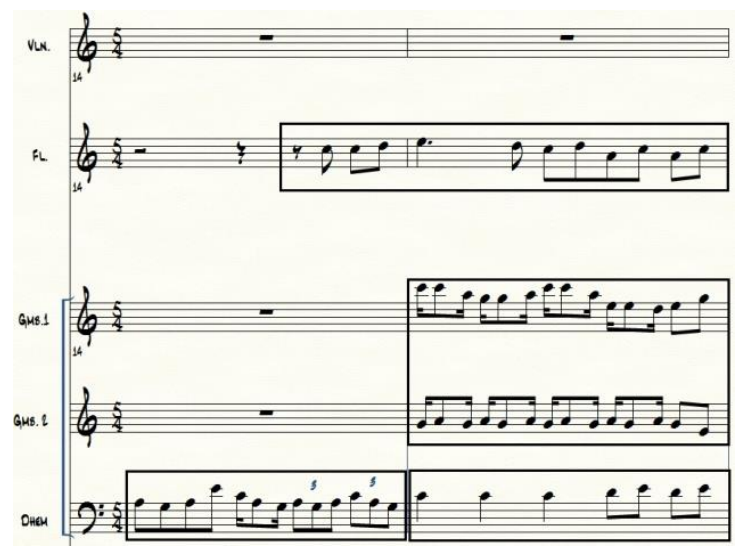

Dilanjutkan dengan motif lain dalam sukat 6/4 yang berfungsi sebagai jembatan untuk masuk dalam bentuk lagu berikutnya. Seperti contoh notasi ini.

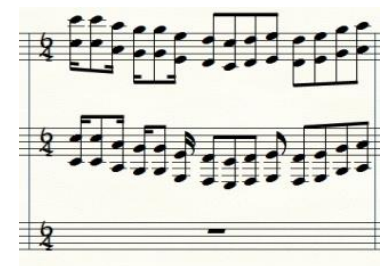

Bentuk lagu baru terbangun dalam satu kesan yang berbeda yang memunculkan kembali tema pokok, dibuka dengan kalimat lagu pendek, seperti pada contoh notasi dibawah ini. 


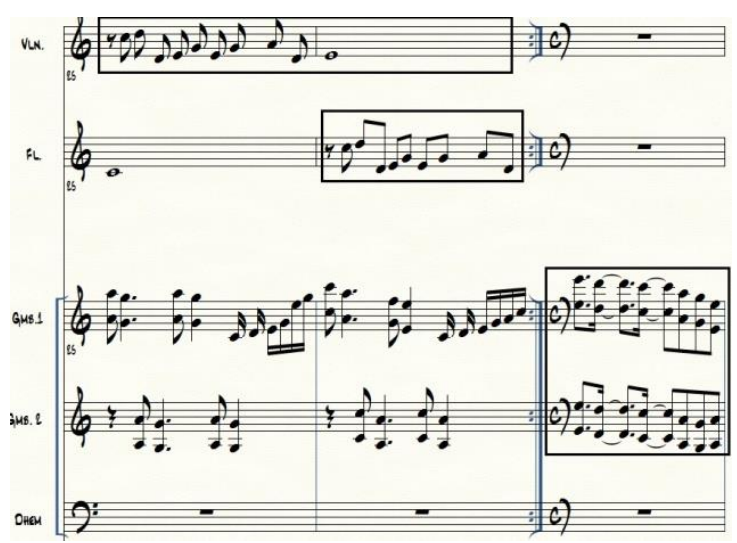

Pada bangunan kalimat lagu ini tema pokok dikembangan menjadi melodi baru yang berfungsi sebagai intro dua sebelum masuk pada bangunan bentuk lagu selanjutnya.

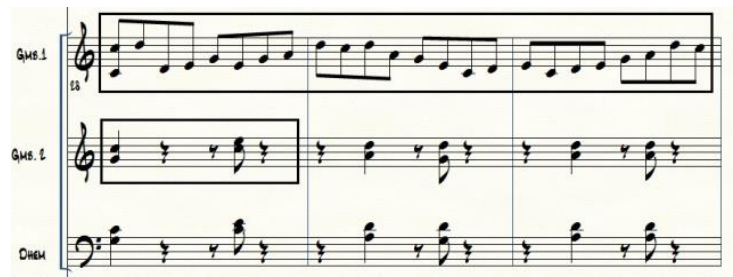

Kemudian melodi baru terbangun sebagai sub tema membentuk kaliamat lagu dalam sukat 3/4 dan menjadi lagu pokok yang didukung iringan oleh instrumen calung yang menggunakan tema pokok yang sudah diperkecil secara nilai nadanya, seperti notasi dibawah ini.

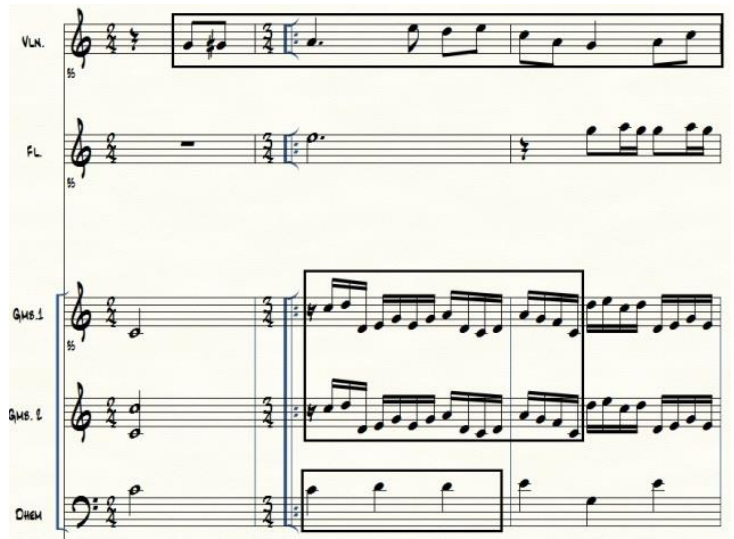

Seterusnya muncul melodi baru pada flute sebagai penutup bagian ini. 


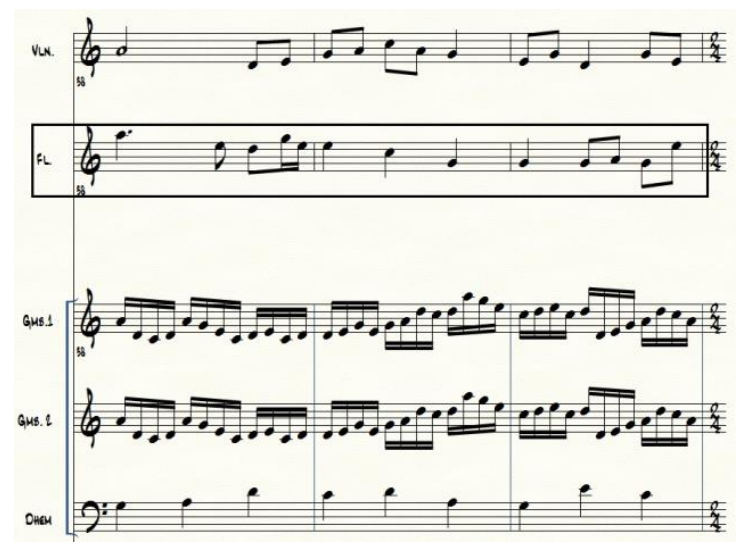

Dilanjutkan dengan bangunan kesan baru berupa motif-motif pendek yang diambil dari modifikasi tema pokok yang dimainkan secara bergantian anatara biola, flute dan ansambel calung membentuk kalimat lagu baru. Kesan menurut Sunarto (2016). Dari segi lain membahas bagaimana keindahan tersebut dapat sampai, dimengerti serta dapat menghasilkan kesan indah bagi pendengarnya. Oleh sebab itu motif-motif selalu dibangun baru dan dikembangkan agar kesan semakin bervariasi.

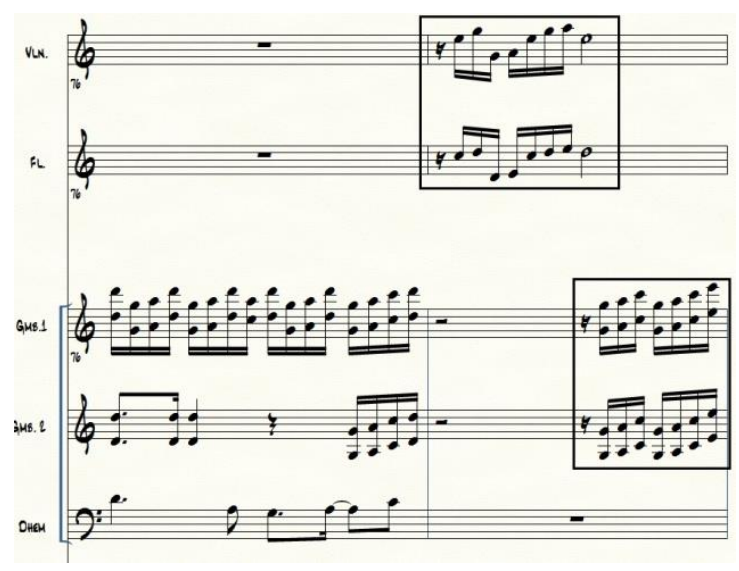

Kemudian motif baru terbangun dalm permainan tonalitas yang dimainkan oleh Biola, flut sedangkan calung memberi aksentuasi sebagi pendukung.

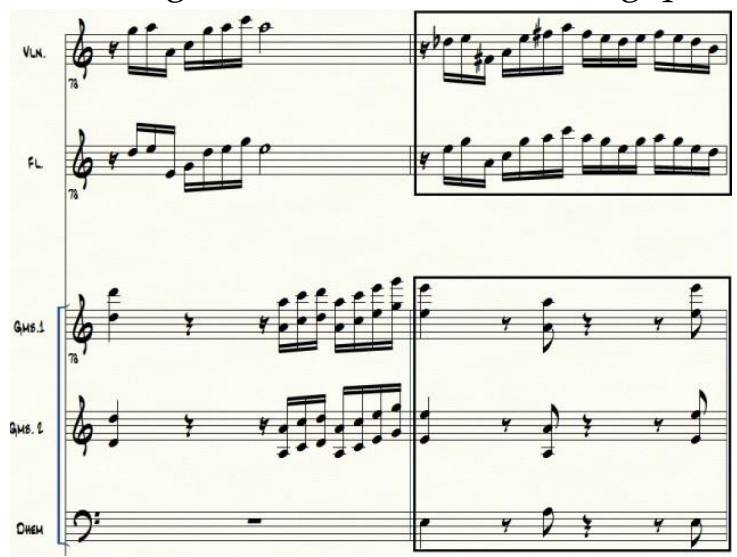

Lanjut melodi baru tersusun menjadi kalimat lagu baru yang didukung oleh motif-motif baru berfungsi sebagai pengiring. 


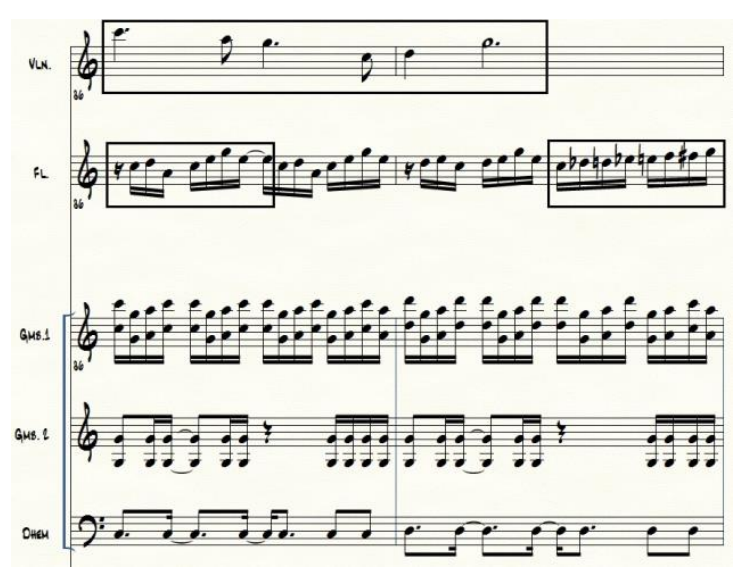

Kemudian kaliamat lagu ditutup dengan dua motif baru,seperti pada contoh notasi dibawah ini.

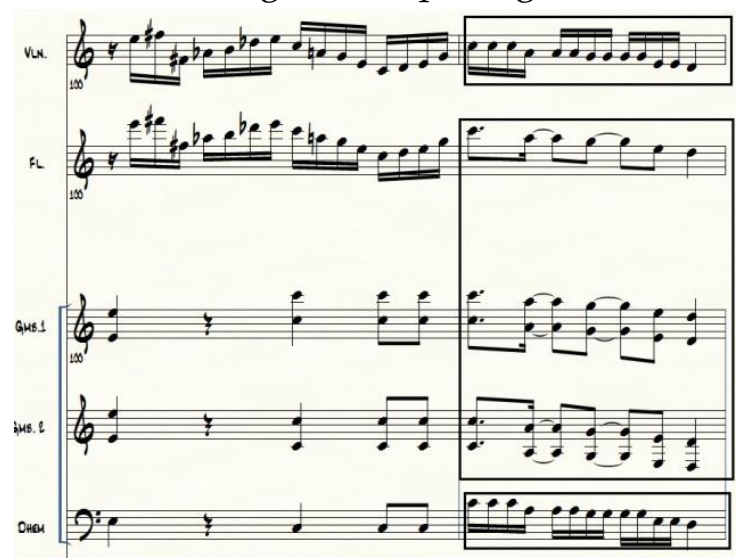

Bangunan bentuk kalimat baru dibuka dengan kesan iringan berupa motif-motif pendek, seperti pada contoh ini.

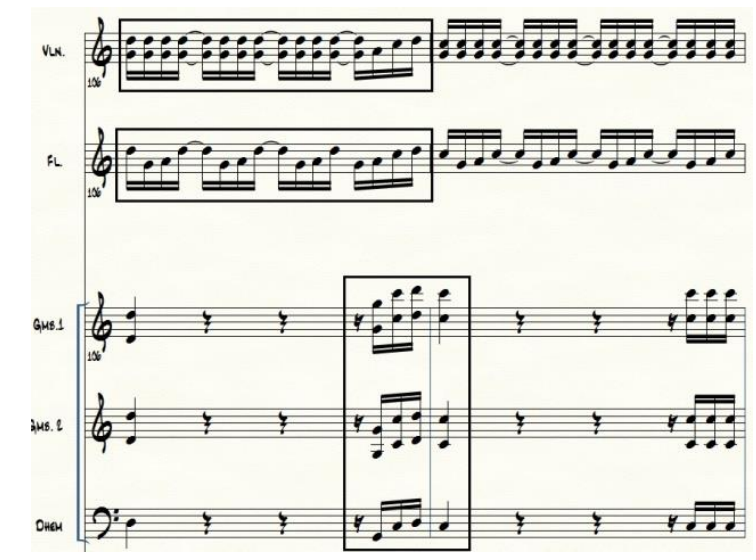


Dilanjutkan dengan munculnya tema pokok yang dibuat kontras ritmikal antara biola dan calung dan masing-masing mempunyai fungsi yang sama.

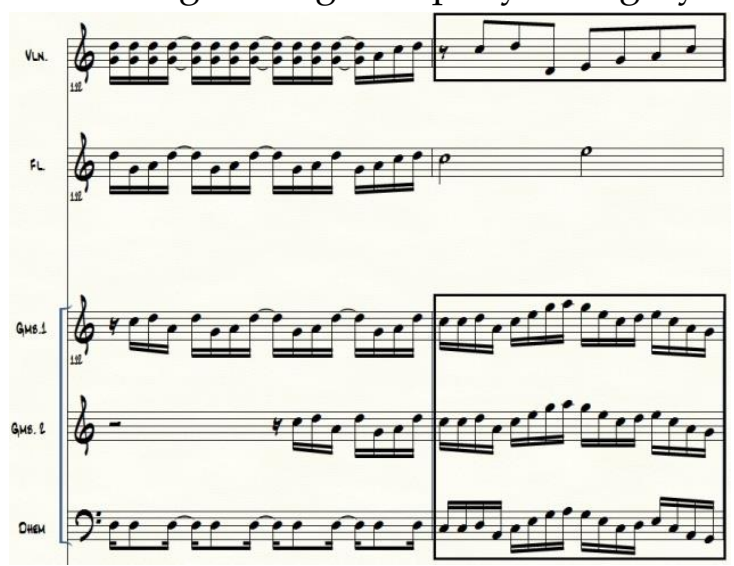

Kemudian tema modifikasi diambil alih oleh biola dan flute dalam satu olahan tonalitas, seperti notasi dibawah ini

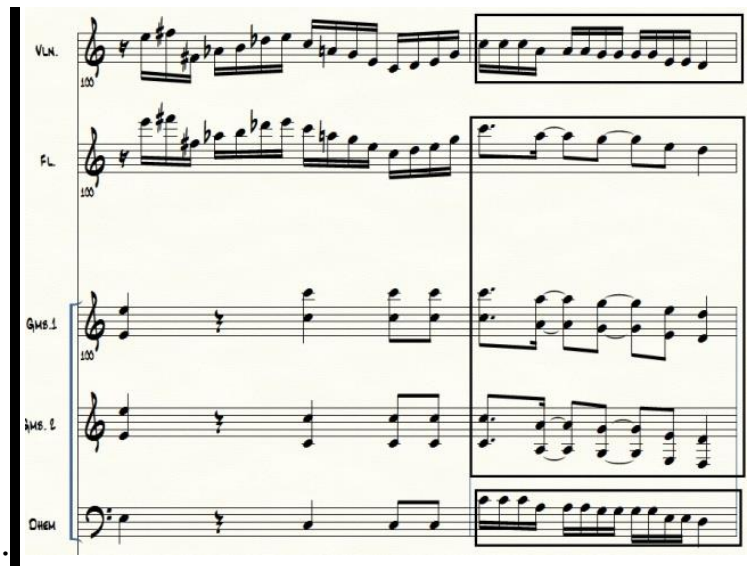

sedangkan calung memainkan aksentuai sebagai pendukung melodi dominan.

Tema pokok yang sudah dimodifikasi muncul lagi, diamainkan oleh ansambel calung secara unisono sedangkan flute dan biola memainkan motif nada-nada panjang sebagai kontras melodinya.

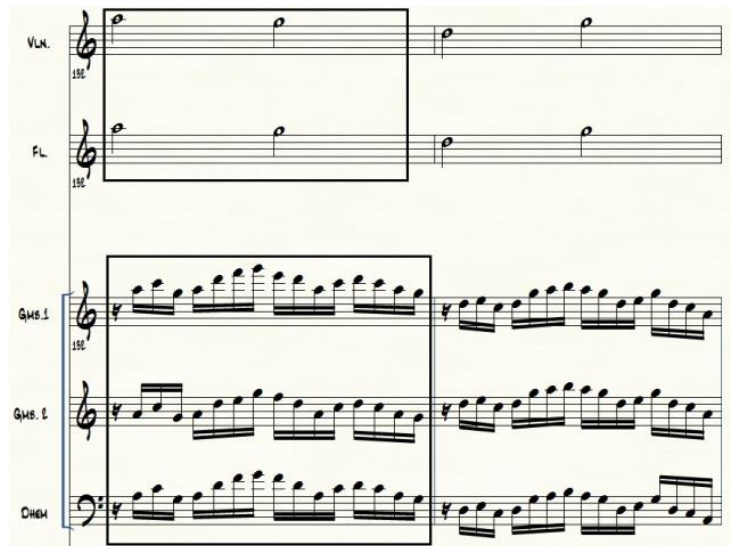

Selanjutnya motif baru terbangun sebagai penegas klimak untuk menutup keseluruhan bagian ketiga ini, seperti contoh notasi dibawah ini. 


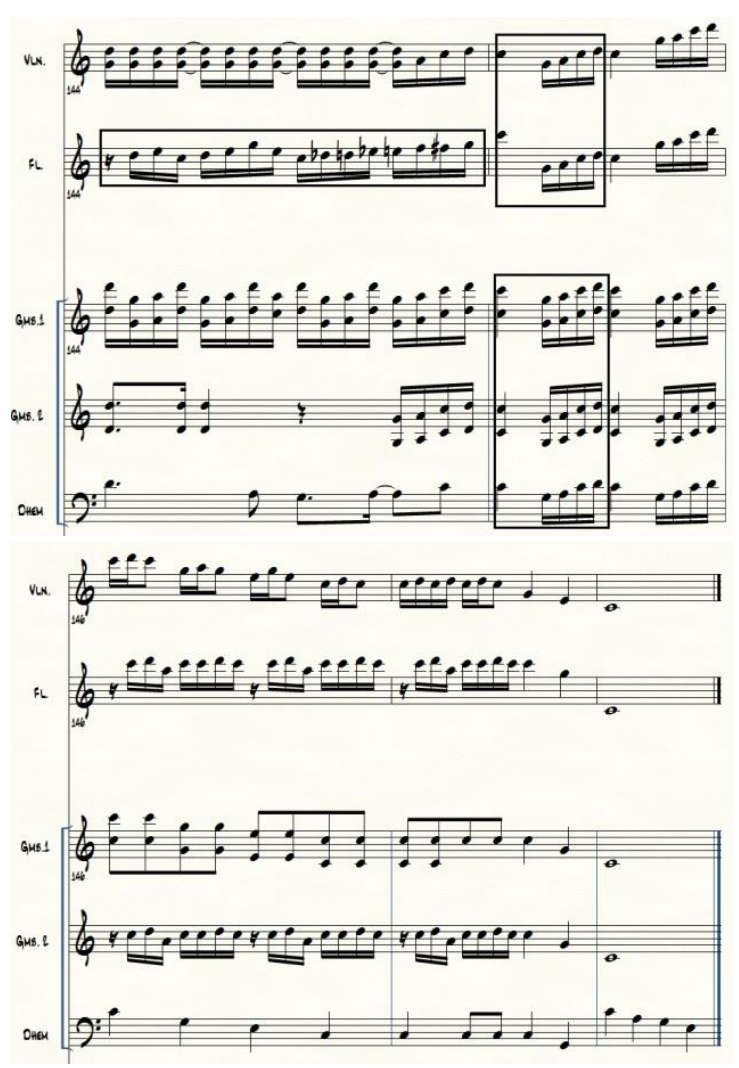

\section{Kesimpulan}

Analisis sebuah karya komposisi musik baru merupakan sebuah kajian yang menarik, karena dalam analisis kita dapat mengerti proses kreativitas dalam penyusunan komposisi dari awal hingga akhir. Pada komposisi musik yang berjudul "Fantasia From Dualolo" ini tema pokok sangat penting sebagai bentukan kesatuan tematik dari keseluruan komposisi, agar bangunan komposisi keseluruhan saling terkait antara satu bagian dan bagian lainya dibutuhkan pendalaman teknik secara kompositorik.

Teknik pengembangan tema dilakukan dengan berbagai cara sesuai dengan hayalan atau fantasi penyusun dalam membangun berbagai kesan. Teknik kompositorik yang digunakan dalam penyunan komposisi ini meliputi augmentasi, diminusi, variasi, harmoni dan penyusunan motifmotif baru dalam berbagai variasi melodi.

Kreativitas dalam penyusunan karya musik ini dapat dijadikan salah satu bukti bagaimana sebuah melodi pendek dari sumber tradisi karawitan Jawa dapat dijadikan tema dan dikembangkan menjadi satu bentuk komposisi baru yang terdiri dari tiga bagian.

Proses analisis ini bersifat perseptif interpretatif yang mana tidak menutup kemungkinan bagi peneliti lain untuk melihat karya komposisi ini dengan cara atau sudut pandang berbeda. 


\section{Daftar Pustaka}

Banoe, Pono. 2003. Kamus Musik. Yogyakarta: Kanisius.

Dasanta, Caecilia Theodora Setiarini. 2017. “'AUTISM' SEBUAH KOMPOSISI MUSIK PROGRAM BERDASAR DARI PERKEMBANGAN KEHIDUPAN ANAK AUTIS.” Institut Seni Indonesia Yogyakarta.

Ganap, Victor. 1986. Pengantar Kearah Apresiasi Musik. Yogyakarta: Debdikbud.

Hadaci, Sidik. 2018. “KOMPOSISI MUSIK 'PIK-PIK-NUMPANG-TIDUK': INTERPRETASI DARI SEBUAH KESENIAN TRADISI LISAN DI DESA PULAU TEMIANG, KABUPATEN TEBO, PROVINSI JAMBI." Jurnal $\quad$ Puitika 14 (2). https://doi.org/http://dx.doi.org/10.25077/puitika.14.2.190--204.2018.

Linggono, Budi. 1993. Bentuk Dan Analisis Musik. Jakarta: Pusat Perbukuan, Depdikbud.

Martapangrawit. 1975. "Pengetahuan Karawitan II." Surakarta.

Martopangrawit. 1972. Cengkok-Cengkok Genderan Jilid II. Surakarta: Akademi Seni Karawitan Indonesia Surakarta.

Miller, Hugh M. 2017. Apresiasi Musik. Edited by Sunarto. 1st ed. Jogjakarta: Panta Rhei Books.

Nainggolan, Oriana Tio Parahita. 2019. “Pembelajaran Musik Kreatif Dalam Sudut Pandang Pembelajaran Abad Ke-21." Promusika: Jurnal Pengkajian, Penyajian Dan Penciptaan Musik 7 (1).

Pambayun, Wahyu Thoyyib. 2020. "Garap Genderan Dalam Gending Lampah Tiga." Keteg, Jurnal Pengetahuan, Pemikiran, Dan Kajian Tentang "Bunyi" 20 (2): 120-30. https://doi.org/https://doi.org/10.33153/keteg.v20i2.3569.

Pasaribu, Amir. 1953. Riwayat Musik Dan Musisi. Jakarta: Gunung Agung.

Primadi. 1978. Proses Kreasi \& Apresiasi Belajar. Bandung: ITB.

Rachman, Abdul. 2013. “Bentuk Dan Analisis Musik Keroncong Tanah Airku Karya Kelly Puspito." Harmonia 13 (1).

Sektian, Jazzy Adam Sila. 2016. “ANALISIS BENTUK DAN STRUKTUR LAGU JEUX D’EAU KARYA MAURICE RAVEL." Universitas Negeri Yogyakarta.

Soeroso. 1983. Gamelan A Dan B. Jakarta: Departemen P dan K, Direktorat Jendral Pendidikan Dasar dan Menengah, Direktorat Menengah Kejuruan.

Sugiyanto, Danis. 2020. “Komposisi Karawitan Ismuning Cahya: Interpretasi Keesaan Tuhan Melalui Tokoh Semar." Keteg, Jurnal Pengetahuan, Pemikiran, Dan Kajian Tentang "Bunyi" 20 (2): 157-67.

Suharto, Suharto. 2018. "Pelestarian Calung Banyumasan Di Masyarakat Kabupaten Banyumas." In Seminar Nasional Struktural 2018, 39-49. Semarang, Indonesia: Dian Nuswantoro University. https://doi.org/10.33810/274159.

Sunarto, Bambang. 2013. Epistemologi Penciptaan Seni. Yogyakarta: Idea Press.

Sunarto, Sunarto. 2016. “Estetika Musik: Autonomis versus Heteronomis Dan Konteks Sejarah Musik." PROMUSIKA 4 (2): 102-16. https:/ / doi.org/10.24821/promusika.v4i2.2278.

Supanggah, Rahayu. 2009. “Bothekan Karawitan II: Garap." Surakarta: ISI Press Surakarta.

Tjaturrini, Dyah. 2018. "CALENGSAI : KREATIVITAS DAN INOVASI PEKERJA SENI DALAM MEMPERTAHANKAN KESENIAN TRADISIONAL.” Jurnal Ilmiah Lingua Idea 9 (2). 